\title{
Die Belasteten
}

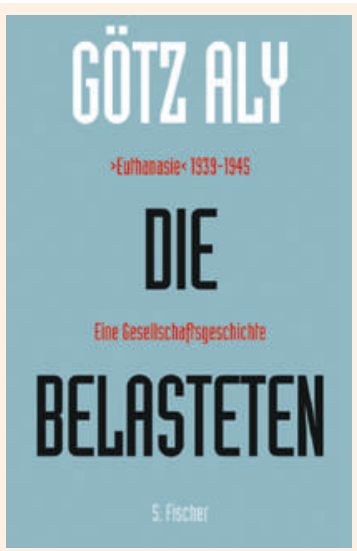

Götz Aly

Die Belasteten

«Euthanasie» 1939-1945: Eine Gesellschaftsgeschichte. Frankfurt a. M.: Fischer Verlag; 2013

348 Seiten. 34,90 CHF. ISBN 978-3-10-000429-1
Korrespondenz:

Dr. med. Enrico Danieli

Via ai Colli 22

CH-6648 Minusio

Tel. 0917434789

e.b.danieli[at]bluewin.ch
«Sie wissen, dass», wie Göbbels in seinem Tagebuch 1941 schreibt, «gänzlich ungeeignete Menschen, die vollkommen verblödet sind und niemals geheilt werden können und mitgeschleppt werden und den Sozialetat des Landes dermassen belasten, dass diese hunderttausend Menschen eine unverhältnismässige Belastung darstellen», wie Göbbels geschrieben hat, dass also solche Menschen durch vom Regime dazu ermächtigte Ärzte, Schwestern und Pfleger in sogenannten Anstalten getötet werden können meist durch Gas und, wie das Tarnwort lautet, durch Desinfektion.

Genau davon handelt das $\mathrm{zu}$ besprechende Buch, das zu kennen sich lohnt, und das gerade heute bei schwindenden Ressourcen an Aktualität gewinnt. Die systematische Ermordung körperlich versehrter (auch, zum Beispiel, tuberkulöser Patienten oder Zehntausender kranker Kinder) oder geistig auffälliger Menschen ist eines derjenigen Kapitel der jüngsten Geschichte, das direkt mit unserem Beruf zu tun hat. Darf, so lautet die Grundsatzfrage, ein Arzt töten? Die Geschichte der Euthanasie-Politik ist heutzutage gut erforscht. (Erwähnenswert, dass in diesem Buch, das die Euthanasie von 1939 bis 1945 untersucht, nie von Euthanasie die Rede ist, sondern lediglich Sterbenden einen leichten Tod - den Gnadentod - gewährt. Abgesehen davon, dass es zum Morden viele materielle Gründe gab, vor allem im Krieg, und nicht im Vordergrund sogenannt erbhygienische Gründe standen, die Ärzte zu Mördern werden liessen, abgesehen davon war nicht wenigen der scheinbar unheilbar kranken oder dementen oder depressiven oder schizophrenen Patienten bewusst, was man mit ihnen vorhatte. Davon zeugen einzigartige, erstmals veröffentlichte Dokumente. Nicht zu vergessen, dass die optimale spurenarme Technik des Tötens, die sogenannte Behandlung zur Fahrt ins Blaue, das beschleunigte Sterben und die Eliminierung, die Liquidation und die Todesspritze einzig von Ärzten erfunden worden waren.

Neu ist die Erkenntnis, dass von den Angehörigen der Todeskandidaten kaum Widerstand ausging obwohl alle alles wussten: In einer Umfrage votierten $70 \%$ der Eltern für die Erlösung ihrer kranken Kinder. Dabei im Zentrum stand die Hoffnung der Angehörigen, im Detail nichts zu erfahren. Getrieben von dem Wunsch nach Gewissensruhe oder Unschuld, gaben sie ihr stillschweigendes Einverständnis. Und erinnerungswürdig bleibt auch die makabre Feststellung, dass viele Ärzte vom Morden

\section{«Was dann folgte, war das, was in den Tod diagnostizieren» genannt wurde.»}

von Morden und Vergasen, Vergiften und Abspritzen, Aushungern und Erschlagen.)

Der Autor, der bekannte Historiker Götz Aly, der sich durch fundierte, oft als provokant empfundene Bücher zur Hitlerzeit einen Namen gemacht hat, beschäftigt sich mit der «Euthanasie». Aly nimmt in seinem eben erschienenen Buch eine andere als übliche Position ein: Er stellt nämlich die Opfer der Mordaktionen in den Mittelpunkt. Jenen Einsamen und Verlassenen, Kranken und Siechen, Missgebildeten und Asozialen, Epileptikern und Tuberkulösen, Psychopathen und Geisteskranken, Arbeitsscheuen und Gemeinschaftsfremden gilt seine Sympathie, also jenen von Göbbels verächtlich gemachten Hunderttausenden von Ballastexistenzen, und nicht ihren Mördern, die später sagen werden (nachdem die meisten von ihnen glänzende Universitätkarrieren begonnen haben), sie hätten nichts gewusst und profitierten, indem sie diesem einen wissenschaftliche Sinn gaben: das Töten zum Zweck der direkten Forschung am Menschen.

Am Anfang allen Tötens wiederholte sich die stets gleiche Frage: arbeitsfähig oder nicht? brauchbar oder unbrauchbar? Was dann folgte, war das, was «in den Tod diagnostizieren» genannt wurde: Denn nichts als ein Luxus war die Erhaltung der Lebensuntüchtigen ... Dies entsprach dem Zukunftsentwurf einer Gesellschaft leistungsstarker, gesunder Menschen - rund zweihunderttausend Opfer haben Schwestern, Pfleger und Ärzte auf dem Gewissen. Ein in seiner Offenheit verstörendes Buch - nicht zuletzt wenn man bedenkt, dass es sich bei den Ärzten nicht nur um im NS-System aufgestiegene Schlächter gehandelt hat, sondern um reformerisch gesinnte (im Sinne der Non-restraint-Bewegung), ihren Patienten also offen zugewandte Mediziner ... 